\title{
Trick or Treat: Microbial Pathogens Evolved Apoplastic Effectors Modulating Plant Susceptibility to Infection
}

\author{
Yan Wang and Yuanchao Wang ${ }^{\dagger}$ \\ Department of Plant Pathology, Nanjing Agricultural University, and Key Laboratory of Integrated Management of Crop \\ Diseases and Pests (Ministry of Education), Nanjing, 210095, China
}

Accepted 9 September 2017.

\begin{abstract}
The apoplastic space between the plant cell wall and the plasma membrane constitutes a major battleground for plant-pathogen interactions. To survive in harsh conditions in the plant apoplast, pathogens must cope with various immune responses. During infection, plant pathogens secrete an arsenal of effector proteins into the apoplast milieu, some of which are detected by the plant surveillance system and, thus, activate plant innate immunity. Effectors that evade plant perception act in modulating plant apoplast immunity to favor successful pathogen infection. The concerted actions of apoplastic effectors often determine the outcomes of plant-pathogen interactions. In this review, we summarize current advances on the understanding of apoplastic effectors and highlight the strategies employed by pathogens to counter host apoplastic defense.
\end{abstract}

Plants are constantly attacked by a wide variety of microbes. Plants are sessile and lack an adaptive immune system. Nevertheless, plants developed a sophisticated innate immune system that is able to circumvent infections by most potential pathogens (Jones and Dangl 2006). The cuticle and cell wall constitute physical barriers to protect plants against microbe penetration (Hückelhoven 2007). Additionally, the plant apoplast is equipped with various hydrolases, protease inhibitors, and antimicrobial compounds to impede microbe infection. Once these barriers are overcome, plant cell surface receptors are activated to sense the invading microbes via detecting the molecular patterns derived from microbes or plants known as microbe-associated molecular patterns (MAMPs) or damage-associated molecular patterns, which ultimately activate pattern-triggered immunity (PTI), including reactive oxygen species (ROS) production, ion fluxes, callose depositions, defense-related gene expression, and secondary metabolite production (Boller and Felix 2009; Jones and Dangl 2006). In the long-term evolution, pathogenic microbes have developed strategies to tackle plant immune responses. The common weapon employed by plant pathogens is secreted effectors that undermine plant immunity and favor successful infection. Such effectors act either in plant apoplast (apoplastic effectors) or inside plant cells (cytoplasmic effectors) to fulfill virulence function. Cytoplasmic effectors are translocated into different cell compartments and interfere with various plant physiological processes, including protein synthesis or secretion,

${ }^{\dagger}$ Corresponding author: Yuanchao Wang; E-mail: wangyc@njau.edu.cn

(c) 2018 The American Phytopathological Society
ROS production, secondary metabolites synthesis, mitogenactivated protein kinase activation, as well as epigenetic modifications (Dong et al. 2011; Kong et al. 2017; Liu et al. 2014; Lo Presti et al. 2015; Tanaka et al. 2014; Whisson et al. 2016). Nonetheless, the initial interactions between plants and microbes occur in the plant apoplast, which hosts extracellular plant pathogens as well as the feeding structures of multiple filamentous pathogens. The action of apoplastic effectors often plays a determinant role in plant-pathogen interactions. Here, we briefly summarized the recent findings on how apoplastic effectors function during plant-pathogen interactions.

\section{MODULATE PLANT CELL WALLS AND ASSOCIATED DEFENSE}

Plant cell walls are rigid matrices that are composed of cellulose, pectin, hemicelluloses, lignin, and structural proteins. To establish infection, microbial pathogens must confront the physical barriers of plant cell walls. Genome sequencing revealed that many pathogens encode a plethora of cell walldegrading enzymes (CWDEs) with a potential role in decomposing plant cell walls (Bellafiore et al. 2008; Kamper et al. 2006; Kubicek et al. 2014; Zhao et al. 2013). For example, the biotrophic corn smut fungus Ustilago maydis contain 33 such CWDE-encoding genes (Kamper et al. 2006), while the hemibiotrophic rice blast fungus Magnaporthe grisea and the necrotrophic Fusarium head blight fungus Fusarium graminearum contain even more, with 138 and 103 CWDE-encoding genes, respectively (Kamper et al. 2006). For all pathogens, regardless of lifestyle, breaching plant cell wall is essential to acquire nutrients and establish a successful infection. CWDEs target multiple plant polysaccharides and many CWDEs are indispensible for pathogen virulence, especially for necrotrophic pathogens, which extensively macerate plant tissues during infection (Brito et al. 2006; Isshiki et al. 2001; Kubicek et al. 2014; Noda et al. 2010; Oeser et al. 2002; Valette-Collet et al. 2003).

The cell wall-plasma membrane (CW-PM) integrity is important for cell wall sensory signaling and plant defense. RGD (R: arginine; G: glycine; D: aspartic acid) motif-containing peptides are well known to interfere with cell adhesion in animals and to disrupt CW-PM adhesions in plants (Canut et al. 1998; Ruoslahti 1996; Senchou et al. 2004). Application of RGD motif-containing peptides disrupted cell wall-associated defense responses and enabled increased pathogen penetration (Mellersh and Heath 2001). IPI-O is an RGD-containing effector belonging to a large family of Phytophthora effectors that share the host cell-targeting motif RXLR (Champouret 
et al. 2009). IPI-O possessed high binding affinity to an Arabidopsis membrane protein and disrupted CW-PM adhesions in plasmolysed Arabidopsis cells (Canut et al. 1998; Senchou et al. 2004). A screen for IPI-O binding protein in Arabidopsis led to the identification of LecRK-I.9, a potential target of IPI-O that plays a role in mediating CW-PM adhesions (Bouwmeester et al. 2011; Gouget et al. 2006). Constitutive expression of ipiO or knockout of LecRK-I.9 in Arabidopsis disrupted CW-PM integrity and significantly reduced the bacterial MAMP flg22-triggered defense as well as resistance to Phytophthora pathogens (Bouwmeester et al. 2011).

\section{TRIGGER PLANT INNATE IMMUNITY}

Of the apoplastic effector repertories, a certain amount can be detected by plants as elicitors and evoke plant defense responses (Boller and Felix 2009). Such effectors are either proteinaceous elicitors that are highly conserved among microbial taxa or race-specific avirulence proteins secreted by extracellular fungal plant pathogens. The necrosis- and ethylene-inducing peptide 1-like proteins (NLPs) present in a broad spectrum of microbial organisms are cytotoxic effectors that trigger necrosis in multiple dicotyledonous plants (Fellbrich et al. 2002). NLPs bear a conserved 20-amino acid motif (nlp20) that can be perceived by the membrane-localized leucine-rich repeat (LRR) receptor RLP23 and mounts PTI responses specifically in Brassicaceae plants (Albert et al. 2015; Boehm et al. 2014). PsXEG1 is a recently identified
MAMP from the culture filtrates of the oomycete pathogen Phytophthora sojae (Ma et al. 2015). PsXEG1 can be solely recognized in plant apoplast which requires the LRR receptorlike protein RXEG1 (Ma et al. 2015; Y. Wang, Y. Xu, Y. Sun, H. Want, J. Zi, B. Wan, Y. Shao, Y. Lin, W. Ye, S. Dong, B. M. Tyler, and Y. Wang unpublished) (Fig. 1). Recognition of XEG1 triggers cell death in multiple dicot plants, including Nicotiana benthamiana, tomato, pepper, and soybean but not in maize or cotton. PsXEG1 belongs to the glycoside hydrolase 12 (GH12) protein family, which is widely distributed across microbial taxa but absent in plants. Interestingly, GH12 protein family is largely expanded in Phytophthora species and approximately half of the identified GH12 proteins trigger cell death in N. benthamiana (Ma et al. 2015). The tomato leaf mold pathogen Cladosporium fulvum is an extracellular fungal pathogen that releases dozens of small secreted effectors into the apoplast during infection (de Wit 2016; Mesarich et al. 2017). Several race-specific avirulence effectors, such as Avr2, Avr4, Avr4E, Avr5, and Avr9, can be recognized by tomato lines carrying the cognate $C$. fulvum resistance genes (de Wit 2016). Recently, a survey of 63 putative apoplastic effectors secreted by the Septoria tritici blotch disease agent Zymoseptoria tritici revealed that 13 effectors can be recognized by $N$. benthamiana and trigger cell death (Kettles et al. 2017). The plant parasitic nematodes also deliver apoplastic effectors during infection of plants. GrEXPB2, secreted by the potato cyst nematode Globodera rostochiensis, triggers cell death in multiple plant species, including potato, tomato, and $N$. benthamiana (Ali et al. 2015). Other well-described apoplastic effectors acting as

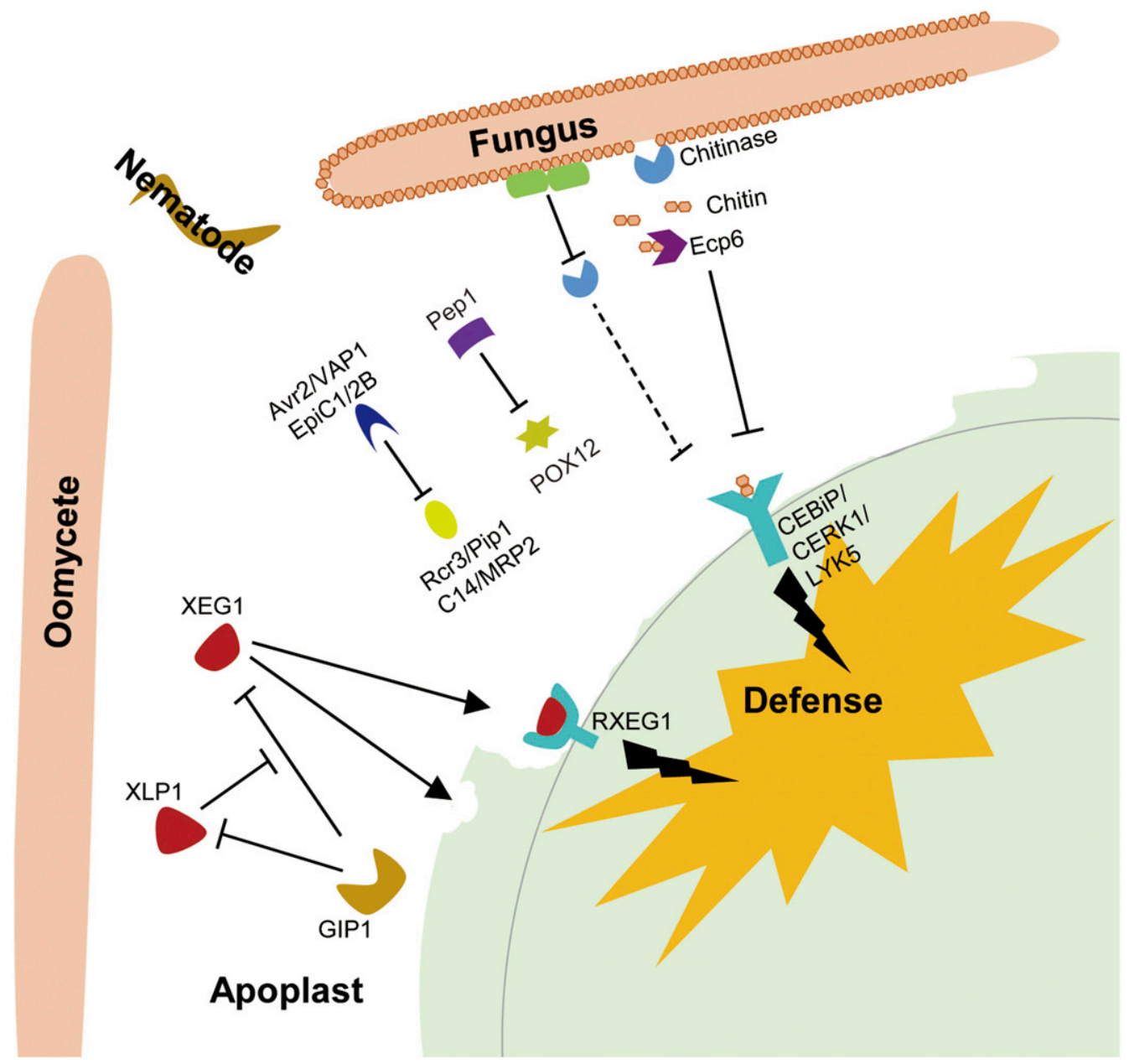

Fig. 1. Microbial effectors modulate plant immunity in the apoplast. Secreted apoplastic effectors in counteracting plant immunity vary depending on the microbial species. Modes of action of several apoplastic effectors with their corresponding plant partners are depicted, based on current knowledge. 
potent elicitors of plant defenses include the bacterial MAMP eMax from xanthomonads, fungal endopolygalacturonases, the Sclerotinia sclerotiorum elicitor SCFE1, fungal ethylene-inducing xylanase (EIX), Ave1 (avirulence on Ve1 tomato) present in race 1 strains of Verticillium spp., and the Phytophthora elicitin INF1, and these elicitors are recognized by the immune receptors Arabidopsis RLP1, RLP42, RLP30, tomato Eix2, Ve1, and potato ELR, respectively (de Jonge et al. 2012; Du et al. 2015; Jehle et al. 2013; Kamoun et al. 1998; Ron and Avni 2004; Zhang et al. 2013, 2014). To be noted, all immune receptors identified thus far that sense the secreted apoplastic effectors belong to the superfamily of receptor-like proteins with LRRs in their extracellular domains. Such receptors lack obvious cytoplasmic signal transduction domains and often associate with the receptor-like kinases SOBIR1 or BAK1 or both to activate the cytosolic signaling (Liebrand et al. 2014; Albert et al. 2015).

\section{UNDERMINE PLANT PTI BY INTERFERING WITH MAMP PERCEPTION, SIGNAL TRANSDUCTION, AND DEFENSE EXECUTION}

Activation of immune responses in plants upon perception of microbial patterns often compromises microbe colonization. Thus, adapted microbes have evolved virulence effectors to downregulate PTI basal responses in plants. A well-studied example is the modulation of chitin-induced plant immunity by fungal apoplastic effectors. Plants secrete apoplastic hydrolytic enzymes such as chitinases, which target plant cell-wall components to release soluble chitin oligosaccharides and damage fungal cell-wall integrity (Schlumbaum et al. 1986). Chitin oligosaccharides are perceived as MAMPs by plant membrane receptors with the extracellular lysine motif (LysM) and trigger the dimerization of chitin receptors to initiate PTI (Cao et al. 2014; Hayafune et al. 2014; Kaku et al. 2006; Liu et al. 2012) (Fig. 1). In response, fungal pathogens secrete effectors interfering with plant recognition of chitin and blocking chitininduced plant immunity (Fig. 1). For example, the C. fulvum effector Avr4 contains an invertebrate chitin-binding domain that is able to bind chitin and protect the cell walls of chitinous fungal pathogens, including Trichoderma viride and Fusarium solani, from hydrolysis by plant chitinases (van den Burg et al. 2006). Moreover, the chitin-binding activity of Avr4 inhibits the release of soluble chitin oligomers, thus preventing the activation of chitin-induced plant immunity (Fig. 1). Ectopic expression of Avr4 increased Arabidopsis susceptibility to the chitinous fungal pathogens but not to the bacterial or oomycete pathogens lacking chitinous cell walls (van Esse et al. 2007), indicating that Avr4 promotes virulence via countering chitininduced plant defense. Avr4 homologs are also present in relatives of $C$. fulvum and the Avr4 homolog in the banana pathogen Mycosphaerella fijiensis was proved to play a conserved role in protecting fungal cell walls against plant chitinases (Stergiopoulos et al. 2010). Ecp6 (extracellular protein 6) is another chitin-binding effector secreted by $C$. fulvum during infection (Bolton et al. 2008). Similarly to Avr4, Ecp6 is also required for full virulence of $C$. fulvum on tomato. Rather than shielding fungal cell wall against plant chitinases, Ecp6 sequesters chitin oligosaccharides released from the cell walls of invading fungi, thereby preventing activation of chitin-induced plant immunity (de Jonge et al. 2010). Similarly to the chitin receptors, Ecp6 also contains LysM domains, termed LysM1, LysM2, and LysM3. Crystallography and biochemical analyses revealed that two of the three LysM domains (i.e., LysM1 and LysM3) of Ecp6 undergo ligand-induced dimerization to form a deeply buried groove that binds chitin oligosaccharides with ultra-high affinity $(\mathrm{Kd}=280 \mathrm{pM})$ (Sanchez-Vallet et al. 2013). This is much higher than the chitin-binding affinity of any known chitin-receptors, such as CEBiP, AtCERK1, AtLYK5 (Cao et al. 2014; Liu et al. 2012; Shibuya et al. 1993), which makes Ecp6 effective to outcompete the chitin receptors in terms of chitinbinding during pathogen infection. The central LysM2 domain exhibits a lower chitin-binding affinity, but, nevertheless, mutations in the putative chitin-binding site of this LysM domain abolishes Ecp6-mediated suppression of chitin-induced plant immunity (Sanchez-Vallet et al. 2013). Thus, the LysM2 domain is indispensable and probably acts in perturbing the dimerization of chitin receptors. Emerging evidence suggests that modulation of chitin recognition by the LysM effectors is a common strategy employed by fungal pathogens to achieve infection (Fig. 1). Putative effectors with varying numbers of LysM repeats are widely distributed across the fungal kingdom (de Jonge and Thomma 2009). The apoplastic LysM effector Slp1, secreted by the rice blast pathogen Magnaporthe oryzae, was shown to function in a manner similar to Ecp6 (Mentlak et al. 2012). Slp1 binds specifically to chitin and competes for chitinbinding with plant chitin receptors to suppress chitin-induced immunity. The wheat pathogen Mycosphaerella graminicola contains three LysM effectors, and two of these, i.e., Mg1LysM and $\mathrm{Mg} 3 \mathrm{LysM}$ are highly induced during early infection phase (Marshall et al. 2011). Both are able to protect fungal hyphae against plant chitinases, whereas only Mg3LysM acts in suppressing activation of chitin-induced immunity.

Perception of microbial attack by plants triggers an array of immune responses (Boller and Felix 2009). As such, pathogens often interfere with components of the plant defense-generating system. Rapid accumulation of ROS is a hallmark of PTI elicitation (Dixon et al. 1994). Pep1 (Protein essential during penetration 1), a conserved apoplastic effector secreted by U. maydis and the related smut fungus Ustilago hordei, targets a key enzyme of the maize ROS-generating system, namely peroxidase 12 (POX12) (Fig. 1), and inhibits the oxidative burst triggered by pathogen infection (Doehlemann et al. 2009; Hemetsberger et al. 2012, 2015). Deletion of Pepl induced various plant immune responses and completely blocked the penetration of the two smut fungi (Doehlemann et al. 2009). Intriguingly, the $\Delta$ pep 1 mutant regained the ability to penetrate maize seedlings after treatment with ROS scavenger (Hemetsberger et al. 2012), indicating that shutting down the accumulation of ROS by Pep1 is sufficient to establish a compatible interaction.

\section{INHIBIT HOST-SECRETED PROTEASES}

The plant apoplast is enriched with secreted proteases that are extensively involved in plant basal immunity (Jashni et al. 2015; van der Hoorn 2008). For example, knockout of the RD21 gene that encodes a papain-like cysteine protease increases the susceptibility of Arabidopsis to the necrotrophic fungal pathogen Botrytis cinerea (Shindo et al. 2012). Adapted plant pathogens, however, secrete effectors working as inhibitors of host proteases to promote disease progression. The apoplastic effector Pit 2 secreted by $U$. maydis inhibits four cysteine proteases implicated in maize defense and contributes to the full virulence of $U$. maydis on maize (Mueller et al. 2013). Rcr3, a papain-like cysteine protease of tomato, is essential for recognizing the apoplastic effector Avr2 by the tomato Cf- 2 resistance protein. Disruption of Rcr3 in tomato leads to the loss of Cf-2-mediated resistance to C. fulvum and the root nematode Globodera rostochiensis as well as the Cf-2-independent resistance to the oomycete pathogen Phytophthora infestans (Dixon et al. 2000; Lozano-Torres et al. 2012; Song et al. 2009). Biochemical analyses demonstrated that Rcr3 is a central hub targeted by several effectors secreted by unrelated pathogens. These include the C. fulvum Avr2, P. infestans cystatin-like 
protease inhibitor EpiC1 and EpiC2B, the root nematode Globodera rostochiensis secreted effector Gr-VAP1, and the Pseudomonas syringae pv. tomato DC3000-secreted Cip1 (Lozano-Torres et al. 2012; Rooney et al. 2005; Shindo et al. 2016; Song et al. 2009). These effectors bind to Rcr3 and inhibit Rcr3 action (Fig. 1). There is also ample evidence showing that a single effector targets multiple plant resistant proteases. Besides inhibiting Rcr3, Gr-VAP1 also perturbs the cysteine protease $\mathrm{C} 14$ in potato (Lozano-Torres et al. 2014). Both EpiC1 and EpiC2B target and selectively inhibit the $\mathrm{C} 14$ in potato and tomato (Kaschani et al. 2010), while EpiC2B also targets Pip1 (Phytophthora inhibited protease 1), a protease that is closely related to Rcr3 and responsive to salicylic acid analog BTH and $P$. infestans infection (Tian et al. 2007). Likewise, C. fulvum Avr2 selectively binds Pip1 and other proteases, including C14 (alias TDI-65), aleurain, and glycinain (van Esse et al. 2008), while Cip1 inhibits C14 and Pip1 (Shindo et al. 2016).

Interestingly, both the proteases and the proteases-inhibitor effectors undergo diversifying selection (Dong et al. 2014; Hörger et al. 2012; Kaschani et al. 2010), indicating that these two partners contribute to the plant-pathogen arms race. For example, diversifying selection on Rcr3 abolished the inhibition by Avr2. Natural variation analysis of Rcr3 revealed that a single amino acid substitution (N194D) makes Rcr3 insensitive to the inhibition by Avr2 and compromises the Rcr3mediated recognition of Avr2 by the tomato $\mathrm{Cf}-2$ protein (Hörger et al. 2012). In addition, the amino acid substitution $\mathrm{R} 213 \mathrm{~S}$ in Rcr3 is associated with insensitivity to Avr2 inhibition but does not affect the recognition of Avr2 by Cf-2. These substitutions, however, are not located in Rcr3 regions involved in binding of other protease-inhibitor effectors, such as $P$. infestans EpiC1/2B (Hörger et al. 2012), indicating that the selection pressures are different according to the challenged pathogens. Moreover, the same pathogen may undergo different selection pressures on different hosts. Sequencing analysis revealed that $\mathrm{C} 14$ is subjected to diversifying selection in wild potato species but conservative selection in wild tomato species (Kaschani et al. 2010). The protease-inhibitor effectors are adapted to selectively take actions to host targets. For example, the binding affinities of EpiCs to $\mathrm{C} 14$ are much higher than those to Rcr3 and Pip1 (Kaschani et al. 2010). By contrast, C. fulvum Avr2 binds strongly to Rcr3 and Pip1 but binds much less strongly to C14 (van Esse et al. 2008). Furthermore, selective pressures shape the protease-inhibitor effectors specialized in inhibiting proteases of their respective host plants. EpiC1 of $P$. infestans exhibits an inhibition specificity distinct from that of its ortholog PmepiC1 of Phytophthora mirabilis, a pathogen of Mirabilis jalapa (Dong et al. 2014). PmepiC1, showed weaker inhibitor activity to tomato Rcr3 but a more efficient inhibition to the Mirabilis Rcr3-like protease 2 (MRP2) (Fig. 1), whereas EpiC1 exhibited the opposite effect. These specificities, however, are attributed to single amino-acid changes in both the protease inhibitor PmepiC1 $\left(\mathrm{Gln}^{111}\right)$ and the substrate MRP2 (Asp152), illustrating that adaptation of protease-inhibitor effectors to their protease targets specializes these two Phytophthora species into their respective hosts.

\section{EVOLVED DECOYS TO TRAP PLANT INHIBITORS}

Plant protease inhibitors comprise an essential element in plant immunity that operates through inhibiting the actions of pathogen proteases or modulating the activities of endogenous plant proteases. To cope with plant immunity, pathogens are often driven by selective pressures to develop new infection strategies. A recent breakthrough in the field of plant-pathogen interactions is the finding that Phytophthora pathogens evolved the decoy effector XLP1 to shield the virulence effector XEG1 against plant defense(Ma et al. 2017) (Fig. 1). XEG1 functions both as a MAMP and an essential virulence effector of Phytophthora spp. (Ma et al. 2015, 2017). Silencing or deletion of PSXEG1 compromises $P$. sojae infection on soybean. PsXEG1 contains a glycoside hydrolase family 12 (GH12) domain, which harbors the xyloglucanase activity. The enzymatic activity is not required for PsXEG1 recognition by plants but is essential for PsXEG1 to fulfill the virulence function during infection. Biochemical assays revealed that PsXEG1 is a target of a xyloglucan-specific endoglucanase inhibitor protein, referred to GmGIP1. GmGIP1 binds to PsXEG1 both in vitro and in vivo and strongly inhibits the xyloglucanase activity of PsXEG1. In accordance, expression of GmGIP1 disrupts PsXEG1-mediated Phytophthora virulence, indicating that GmGIP1 blocks PsXEG1 virulence function by means of direct inactivation of its enzymatic activity. Interestingly, P. sojae also produces a PsXEG1-like protein (PsXLP1) with a truncated GH12 domain and lacking xyloglucanase activity. During Phytophthora infection, PsXLPl shows an expression pattern similar to that of PSXEG1. PsXLP1 also binds to GmGIP1 and shares the same binding sites with PsXEG1. Isothermal titration calorimetry assay revealed that PsXLP1 exhibits a much greater binding affinity to GmGIP1 than did PsXEG1 in vitro. In line with this data, PsXLP1 effectively competes with PsXEG1 for GmGIP1 binding in vivo. Similarly to PsXEG1, PsXLP1 contributes to Phytophthora virulence but in a PsXEG1-dependent manner. Together, these data demonstrate that PsXLP1 acts as a decoy, occupying the GmGIP1 binding sites, that allows PsXEG1 to fulfill its virulence function. The $P S X L P 1$ and $P S X E G 1$ genes abut in a head-tohead manner in the $P$. sojae genome and, indeed, in the genomes of many other Phytophthora species. XLP1 and XEG1 in Phytophthora parasitica exhibit modes of action identical to their $P$. sojae homologs during infection of the host $N$. benthamiana. These data collectively illustrate a conserved strategy employed by Phytophthora pathogens of deploying pseudo-effectors as decoys to sentinel virulence effectors against plant immunity.

\section{REPROGRAM HOST METABOLISM}

Antimicrobial components residing in the apoplast provide an efficient barrier to stop infection of potential pathogens. Saponins, such as glycosylated triterpenoid, steroid, or steroidal alkaloid molecules, produced by plants form complexes with microbial membrane sterols and compromise the membrane integrity in target organisms (Osbourn 1996). Saponins, such as avenacins and $\alpha$-tomatine, are common constitutive antimicrobial compounds required for plant basal defense against various pathogens. For example, the oat species that lacks avenacins showed compromised resistance to the root-infecting fungi Gaeumannomyces graminis and Fusarium pathogens (Papadopoulou et al. 1999). In many cases, plant pathogens produce detoxifying enzymes to remove these antimicrobial obstacles. The oat-attacking variant of Gaeumannomyces graminis produces the saponin-detoxifying enzyme avenacinase to achieve successful infection of oat (Osbourn et al. 1995). $\alpha$-Tomatine is an antimicrobial glycoalkaloid of the basal tomato defense. To counteract this defense, pathogens, including Fusarium oxysporum f. sp. lycopersici, C. fulvum and B. cinerea, secrete tomatinases during infection (Okmen et al. 2013; Pareja-Jaime et al. 2008; Quidde et al. 1998; RoldánArjona et al. 1999). These tomatinases detoxify the apoplastic $\alpha$-tomatine into less-toxic breakdown products such as tomatidine and oligosaccharide lycotetraose (Ito et al. 2004; Ökmen et al. 2013). Thus, C. fulvum and Fusarium oxysporum f. sp. 
lycopersici strains lacking the glycosyl hydrolase family 10 tomatinases become less virulent on tomato (Ökmen et al. 2013; Pareja-Jaime et al. 2008), indicating that modulating plant metabolism is an essential virulence strategy of microbial pathogens to establish disease.

\section{CONCLUDING REMARKS}

As a major interface for plant-pathogen interaction, a continuous arms race is at play in the plant apoplast. To survive in the harsh apoplast, adapted pathogens must overcome MAMPtriggered plant immunity, detoxify antimicrobial compounds, and inhibit plant hydrolases. Over the past decade, genome sequencing has greatly accelerated the identification of secreted effectors. Tremendous advances have been made in our understanding of the modes of action of certain apoplastic effectors. However, given the great variety of secreted effector proteins in the plant apoplast, functions of the majority in terms of plantpathogen interplay remain elusive. Moreover, the temporal regulation, secretion, as well as plant perception of apoplastic effectors require more attention. Overall, such knowledge is instrumental in the development of new chemical agents and novel resistance resources to achieve sustainable plant resistance.

\section{ACKNOWLEDGMENTS}

This work was supported by grants to Yuanchao Wang from the China Natural Science Foundation for Distinguished Young Scientists (grant number 31225022) and for Innovative Research Groups (grant number 31721004) and to Yan Wang from the National Natural Science Foundation of China (grant number 31501622) and from Nanjing Agricultural University (grant number KJQN201663)

\section{LITERATURE CITED}

Albert, I., Boehm, H., Albert, M., Feiler, C.E., Imkampe, J., Wallmeroth, N., Brancato, C., Raaymakers, T.M., Oome, S., Zhang, H., Krol, E., Grefen, C., Gust, A.A., Chai, J., Hedrich, R., Van den Ackerveken, G., and Nuernberger, T. 2015. An RLP23-SOBIR1-BAK1 complex mediates NLP-triggered immunity. Nat. Plants 1 . Published online.

Ali, S., Magne, M., Chen, S., Côté, O., Stare, B. G., Obradovic, N., Jamshaid, L., Wang, X., Bélair, G., and Moffett, P. 2015. Analysis of putative apoplastic effectors from the nematode, Globodera rostochiensis, and identification of an expansin-like protein that can induce and suppress host defenses. PLoS One 10:e0115042.

Bellafiore, S., Shen, Z., Rosso, M.-N., Abad, P., Shih, P., and Briggs, S. P. 2008. Direct identification of the Meloidogyne incognita secretome reveals proteins with host cell reprogramming potential. PLoS Pathog. 4.

Boehm, H., Albert, I., Oome, S., Raaymakers, T. M., Van den Ackerveken, G., and Nuernberger, T. 2014. A conserved peptide pattern from a widespread microbial virulence factor triggers pattern-induced immunity in Arabidopsis. PLoS Pathog. 10:e1004491.

Boller, T., and Felix, G. 2009. A renaissance of elicitors: Perception of microbe-associated molecular patterns and danger signals by patternrecognition receptors. Annu. Rev. Plant Biol. 60:379-406.

Bolton, M. D., van Esse, H. P., Vossen, J. H., de Jonge, R., Stergiopoulos, I., Stulemeijer, I. J. E., van den Berg, G. C. M., Borrás-Hidalgo, O., Dekker, H. L., de Koster, C. G., de Wit, P. J. G. M., Joosten, M. H. A. J., and Thomma, B. P. H. J. 2008. The novel Cladosporium fulvum lysin motif effector Ecp6 is a virulence factor with orthologues in other fungal species. Mol. Microbiol. 69:119-136.

Bouwmeester, K., de Sain, M., Weide, R., Gouget, A., Klamer, S., Canut, H., and Govers, F. 2011. The lectin receptor kinase LecRK-I.9 is a novel Phytophthora resistance component and a potential host target for a RXLR effector. PLoS Pathog. 7:e1001327.

Brito, N., Espino, J. J., and Gonzalez, C. 2006. The endo- $\beta-1,4-x y l a n a s e$ xyn11A is required for virulence in Botrytis cinerea. Mol. Plant-Microbe Interact. 19:25-32.

Canut, H., Carrasco, A., Galaud, J. P., Cassan, C., Bouyssou, H., Vita, N., Ferrara, P., and Pont-Lezica, R. 1998. High affinity RGD-binding sites at the plasma membrane of Arabidopsis thaliana links the cell wall. Plant J. 16:63-71.

Cao, Y., Liang, Y., Tanaka, K., Nguyen, C. T., Jedrzejczak, R. P., Joachimiak, A., and Stacey, G. 2014. The kinase LYK5 is a major chitin receptor in Arabidopsis and forms a chitin-induced complex with related kinase CERK1. eLife 3:3.

Champouret, N., Bouwmeester, K., Rietman, H., van der Lee, T., Maliepaard, C., Heupink, A., van de Vondervoort, P. J. I., Jacobsen, E., Visser, R. G. F., van der Vossen, E. A. G., Govers, F., and Vleeshouwers, V. G. A. A. 2009. Phytophthora infestans isolates lacking class I ipiO variants are virulent on Rpi-blb1 potato. Mol. Plant-Microbe Interact. 22: 1535-1545.

de Jonge, R., and Thomma, B. P. H. J. 2009. Fungal LysM effectors: Extinguishers of host immunity? Trends Microbiol. 17:151-157.

de Jonge, R., van Esse, H. P., Kombrink, A., Shinya, T., Desaki, Y., Bours, R., van der Krol, S., Shibuya, N., Joosten, M. H. A. J., and Thomma, B. P. H. J. 2010. Conserved fungal LysM effector Ecp6 prevents chitintriggered immunity in plants. Science 329:953-955.

de Jonge, R., van Esse, H. P., Maruthachalam, K., Bolton, M. D., Santhanam, P., Saber, M. K., Zhang, Z., Usami, T., Lievens, B., Subbarao, K. V., and Thomma, B. P. H. J. 2012. Tomato immune receptor Ve1 recognizes effector of multiple fungal pathogens uncovered by genome and RNA sequencing. Proc. Natl. Acad. Sci. U.S.A. 109:5110-5115.

de Wit, P. J. G. M. 2016. Cladosporium fulvum effectors: Weapons in the arms race with tomato. Annu. Rev. Phytopathol. 54:1-23.

Dixon, M. S., Golstein, C., Thomas, C. M., van Der Biezen, E. A., and Jones, J. D. G. 2000. Genetic complexity of pathogen perception by plants: The example of $R c r 3$, a tomato gene required specifically by $C f-2$. Proc. Natl. Acad. Sci. U.S.A. 97:8807-8814.

Dixon, R. A., Harrison, M. J., and Lamb, C. J. 1994. Early events in the activation of plant defense responses. Annu. Rev. Phytopathol. 32: 479-501.

Doehlemann, G., van der Linde, K., Assmann, D., Schwammbach, D., Hof, A., Mohanty, A., Jackson, D., and Kahmann, R. 2009. Pep1, a secreted effector protein of Ustilago maydis, is required for successful invasion of plant cells. PLoS Pathog. 5:e1000290.

Dong, S., Stam, R., Cano, L. M., Song, J., Sklenar, J., Yoshida, K., Bozkurt, T. O., Oliva, R., Liu, Z., Tian, M., Win, J., Banfield, M. J., Jones, A. M. E., van der Hoorn, R. A. L., and Kamoun, S. 2014. Effector specialization in a lineage of the Irish potato famine pathogen. Science 343:552-555

Dong, S., Yin, W., Kong, G., Yang, X., Qutob, D., Chen, Q., Kale, S. D. Sui, Y., Zhang, Z., Dou, D., Zheng, X., Gijzen, M., Tyler, B. M., and Wang, Y. 2011. Phytophthora sojae avirulence effector Avr3b is a secreted NADH and ADP-ribose pyrophosphorylase that modulates plant immunity. PLoS Pathog. 7:e1002353.

Du, J., Verzaux, E., Chaparro-Garcia, A., Bijsterbosch, G., Keizer, L.C.P., Zhou, J., Liebrand, T.W.H., Xie, C., Govers, F., Robatzek, S., van der Vossen, E.A.G., Jacobsen, E., Visser, R.G.F., Kamoun, S., and Vleeshouwers, V.G.A.A. 2015. Elicitin recognition confers enhanced resistance to Phytophthora infestans in potato. Nat. Plants 1:15034.

Fellbrich, G., Romanski, A., Varet, A., Blume, B., Brunner, F., Engelhardt, S., Felix, G., Kemmerling, B., Krzymowska, M., and Nürnberger, T. 2002. NPP1, a Phytophthora-associated trigger of plant defense in parsley and Arabidopsis. Plant J. 32:375-390.

Gouget, A., Senchou, V., Govers, F., Sanson, A., Barre, A., Rouge, P., PontLezica, R. P., and Canut, H. 2006. Lectin receptor kinases participate in protein-protein interactions to mediate plasma membrane-cell wall adhesions in Arabidopsis. Plant Physiol.140:81-90.

Hayafune, M., Berisio, R., Marchetti, R., Silipo, A., Kayama, M., Desaki, Y., Arima, S., Squeglia, F., Ruggiero, A., Tokuyasu, K., Molinaro, A., Kaku, H., and Shibuya, N. 2014. Chitin-induced activation of immune signaling by the rice receptor CEBiP relies on a unique sandwich-type dimerization. Proc. Natl. Acad. Sci. U.S.A. 111:E404-E413.

Hemetsberger, C., Herrberger, C., Zechmann, B., Hillmer, M., and Doehlemann, G. 2012. The Ustilago maydis effector Pep1 suppresses plant immunity by inhibition of host peroxidase activity. PLoS Pathog. 8: e1002684.

Hemetsberger, C., Mueller, A. N., Matei, A., Herrberger, C., Hensel, G., Kumlehn, J., Mishra, B., Sharma, R., Thines, M., Hückelhoven, R., and Doehlemann, G. 2015. The fungal core effector Pep1 is conserved across smuts of dicots and monocots. New Phytol. 206:1116-1126.

Hörger, A. C., Ilyas, M., Stephan, W., Tellier, A., van der Hoorn, R. A. L., and Rose, L. E. 2012. Balancing selection at the tomato $R C R 3$ guardee gene family maintains variation in strength of pathogen defense. PLoS Genet. 8:e1002813.

Hückelhoven, R. 2007. Cell wall-associated mechanisms of disease resistance and susceptibility. Annu. Rev. Phytopathol. 45:101-127.

Isshiki, A., Akimitsu, K., Yamamoto, M., and Yamamoto, H. 2001. Endopolygalacturonase is essential for citrus black rot caused by Alternaria citri but not brown spot caused by Alternaria alternata. Mol Plant-Microbe Interact. 14:749-757. 
Ito, S., Eto, T., Tanaka, S., Yamauchi, N., Takahara, H., and Ikeda, T. 2004. Tomatidine and lycotetraose, hydrolysis products of $\alpha$-tomatine by Fusarium oxysporum tomatinase, suppress induced defense responses in tomato cells. FEBS Lett. 571:31-34.

Jashni, M. K., Mehrabi, R., Collemare, J., Mesarich, C. H., and de Wit, P. J. G. M. 2015. The battle in the apoplast: Further insights into the roles of proteases and their inhibitors in plant-pathogen interactions. Front. Plant Sci. 6:584.

Jehle, A. K., Lipschis, M., Albert, M., Fallahzadeh-Mamaghani, V., Fürst, U., Mueller, K., and Felix, G. 2013. The receptor-like protein ReMAX of Arabidopsis detects the microbe-associated molecular pattern eMax from Xanthomonas. Plant Cell 25:2330-2340.

Jones, J. D. G., and Dangl, J. L. 2006. The plant immune system. Nature 444:323-329.

Kaku, H., Nishizawa, Y., Ishii-Minami, N., Akimoto-Tomiyama, C., Dohmae, N., Takio, K., Minami, E., and Shibuya, N. 2006. Plant cells recognize chitin fragments for defense signaling through a plasma membrane receptor. Proc. Natl. Acad. Sci. U.S.A. 103:11086-11091.

Kamoun, S., van West, P., Vleeshouwers, V. G. A. A., de Groot, K. E., and Govers, F. 1998. Resistance of Nicotiana benthamiana to Phytophthora infestans is mediated by the recognition of the elicitor protein INF1. Plant Cell 10:1413-1426.

Kamper, J., Kahmann, R., Bolker, M., Ma, L.-J., Brefort, T., Saville, B. J., Banuett, F., Kronstad, J. W., Gold, S. E., Muller, O., Perlin, M. H., Wosten, H. A. B., de Vries, R., Ruiz-Herrera, J., Reynaga-Pena, C. G., Snetselaar, K., McCann, M., Perez-Martin, J., Feldbrugge, M., Basse, C. W., Steinberg, G., Ibeas, J. I., Holloman, W., Guzman, P., Farman, M., Stajich, J. E., Sentandreu, R., Gonzalez-Prieto, J. M., Kennell, J. C., Molina, L., Schirawski, J., Mendoza-Mendoza, A., Greilinger, D., Munch, K., Rossel, N., Scherer, M., Vranes, M., Ladendorf, O., Vincon, V., Fuchs, U., Sandrock, B., Meng, S., Ho, E. C. H., Cahill, M. J., Boyce, K. J., Klose, J., Klosterman, S. J., Deelstra, H. J., Ortiz-Castellanos, L., Li, W., Sanchez-Alonso, P., Schreier, P. H., Hauser-Hahn, I., Vaupel, M., Koopmann, E., Friedrich, G., Voss, H., Schluter, T., Margolis, J., Platt, D., Swimmer, C., Gnirke, A., Chen, F., Vysotskaia, V., Mannhaupt, G., Guldener, U., Munsterkotter, M., Haase, D., Oesterheld, M., Mewes, H.-W., Mauceli, E. W., DeCaprio, D., Wade, C. M., Butler, J., Young, S., Jaffe, D. B., Calvo, S., Nusbaum, C., Galagan, J., and Birren, B. W. 2006. Insights from the genome of the biotrophic fungal plant pathogen Ustilago maydis. Nature 444:97-101.

Kaschani, F., Shabab, M., Bozkurt, T., Shindo, T., Schornack, S., Gu, C., Ilyas, M., Win, J., Kamoun, S., and van der Hoorn, R. A. L. 2010. An effector-targeted protease contributes to defense against Phytophthora infestans and is under diversifying selection in natural hosts. Plant Physiol. 154:1794-1804.

Kettles, G. J., Bayon, C., Canning, G., Rudd, J. J., and Kanyuka, K. 2017. Apoplastic recognition of multiple candidate effectors from the wheat pathogen Zymoseptoria tritici in the nonhost plant Nicotiana benthamiana. New Phytol. 213:338-350.

Kong, L., Qiu, X., Kang, J., Wang, Y., Chen, H., Huang, J., Qiu, M., Zhao, Y., Kong, G., Ma, Z., Wang, Y., Ye, W., Dong, S., Ma, W., and Wang, Y. 2017. A Phytophthora effector manipulates host histone acetylation and reprograms defense gene expression to promote infection. Curr. Biol. 27:981-991.

Kubicek, C. P., Starr, T. L., and Glass, N. L. 2014. Plant cell wall-degrading enzymes and their secretion in plant-pathogenic fungi. Annu. Rev. Phytopathol. 52:427-451.

Liebrand, T. W. H., van den Burg, H. A., and Joosten, M. H. A. J. 2014. Two for all: Receptor-associated kinases SOBIR1 and BAK1. Trends Plant Sci. 19:123-132.

Liu, T., Liu, Z., Song, C., Hu, Y., Han, Z., She, J., Fan, F., Wang, J., Jin, C., Chang, J., Zhou, J.-M., and Chai, J. 2012. Chitin-induced dimerization activates a plant immune receptor. Science 336:1160-1164.

Liu, T., Song, T., Zhang, X., Yuan, H., Su, L., Li, W., Xu, J., Liu, S., Chen, L., Chen, T., Zhang, M., Gu, L., Zhang, B., and Dou, D. 2014. Unconventionally secreted effectors of two filamentous pathogens target plant salicylate biosynthesis. Nat. Commun. 5:4686.

Lo Presti, L., Lanver, D., Schweizer, G., Tanaka, S., Liang, L., Tollot, M., Zuccaro, A., Reissmann, S., and Kahmann, R. 2015. Fungal effectors and plant susceptibility. Annu. Rev. Plant Biol. 66:513-545.

Lozano-Torres, J. L., Wilbers, R. H. P., Gawronski, P., Boshoven, J. C., Finkers-Tomczak, A., Cordewener, J. H. G., America, A. H. P., Overmars, H. A., Van 't Klooster, J. W., Baranowski, L., Sobczak, M., Ilyas, M., van der Hoorn, R. A. L., Schots, A., de Wit, P. J. G. M., Bakker, J., Goverse, A., and Smant, G. 2012. Dual disease resistance mediated by the immune receptor $\mathrm{Cf}-2$ in tomato requires a common virulence target of a fungus and a nematode. Proc. Natl. Acad. Sci. U.S.A. 109:10119-10124.

Lozano-Torres, J. L., Wilbers, R. H. P., Warmerdam, S., Finkers-Tomczak, A., Diaz-Granados, A., van Schaik, C. C., Helder, J., Bakker, J., Goverse,
A., Schots, A., and Smant, G. 2014. Apoplastic venom allergen-like proteins of cyst nematodes modulate the activation of basal plant innate immunity by cell surface receptors. PLoS Pathog. 10:e1004569.

Ma, Z., Song, T., Zhu, L., Ye, W., Wang, Y., Shao, Y., Dong, S., Zhang, Z., Dou, D., Zheng, X., Tyler, B. M., and Wang, Y. 2015. A Phytophthora sojae glycoside hydrolase 12 protein is a major virulence factor during soybean infection and is recognized as a PAMP. Plant Cell 27:2057-2072.

Ma, Z., Zhu, L., Song, T., Wang, Y., Zhang, Q., Xia, Y., Qiu, M., Lin, Y., Li, H., Kong, L., Fang, Y., Ye, W., Wang, Y., Dong, S., Zheng, X., Tyler, B. M., and Wang, Y. 2017. A paralogous decoy protects Phytophthora sojae apoplastic effector PsXEG1 from a host inhibitor. Science 355: 710-714.

Marshall, R., Kombrink, A., Motteram, J., Loza-Reyes, E., Lucas, J., Hammond-Kosack, K. E., Thomma, B. P. H. J., and Rudd, J. J. 2011. Analysis of two in planta expressed LysM effector homologs from the fungus Mycosphaerella graminicola reveals novel functional properties and varying contributions to virulence on wheat. Plant Physiol. 156: 756-769.

Mellersh, D. G., and Heath, M. C. 2001. Plasma membrane-cell wall adhesion is required for expression of plant defense responses during fungal penetration. Plant Cell 13:413-424.

Mentlak, T. A., Kombrink, A., Shinya, T., Ryder, L. S., Otomo, I., Saitoh, H., Terauchi, R., Nishizawa, Y., Shibuya, N., Thomma, B. P. H. J., and Talbot, N. J. 2012. Effector-mediated suppression of chitin-triggered immunity by Magnaporthe oryzae is necessary for rice blast disease. Plant Cell 24:322-335.

Mesarich, C. H., Ökmen, B., Rovenich, H., Griffiths, S. A., Wang, C., Karimi Jashni, M., Mihajlovski, A., Collemare, J., Hunziker, L., Deng, C. H., van der Burgt, A., Beenen, H. G., Templeton, M. D., Bradshaw, R. E., and de Wit, P. J. G. M. 2017. Specific hypersensitive responseassociated recognition of new apoplastic effectors from Cladosporium fulvum in wild tomato. Mol. Plant-Microbe Interact. 31:145-162.

Mueller, A. N., Ziemann, S., Treitschke, S., Aßmann, D., and Doehlemann, G. 2013. Compatibility in the Ustilago maydis-maize interaction requires inhibition of host cysteine proteases by the fungal effector Pit2. PLoS Pathog. 9:e1003177.

Noda, J., Brito, N., and Gonzalez, C. 2010. The Botrytis cinerea xylanase Xyn11A contributes to virulence with its necrotizing activity, not with its catalytic activity. BMC Plant Biol. 10.

Oeser, B., Heidrich, P. M., Muller, U., Tudzynski, P., and Tenberge, K. B. 2002. Polygalacturonase is a pathogenicity factor in the Claviceps purpurea-rye interaction. Fungal Genet. Biol. 36:176-186.

Ökmen, B., Etalo, D. W., Joosten, M. H. A. J., Bouwmeester, H. J., de Vos, R. C. H., Collemare, J., and de Wit, P. J. G. M. 2013. Detoxification of $\alpha$-tomatine by Cladosporium fulvum is required for full virulence on tomato. New Phytol. 198:1203-1214.

Osbourn, A. 1996. Saponins and plant defence-A soap story. Trends Plant Sci. 1:4-9.

Osbourn, A., Bowyer, P., Lunness, P., Clarke, B., and Daniels, M. 1995. Fungal pathogens of oat roots and tomato leaves employ closely related enzymes to detoxify different host plant saponins. Mol. Plant-Microbe Interact. 8:971-978.

Papadopoulou, K., Melton, R. E., Leggett, M., Daniels, M. J., and Osbourn, A. E. 1999. Compromised disease resistance in saponin-deficient plants. Proc. Natl. Acad. Sci. U.S.A. 96:12923-12928.

Pareja-Jaime, Y., Roncero, M. I. G., and Ruiz-Roldán, M. C. 2008. Tomatinase from Fusarium oxysporum f. sp. lycopersici is required for full virulence on tomato plants. Mol. Plant-Microbe Interact. 21:728-736.

Quidde, T., Osbourn, A. E., and Tudzynski, P. 1998. Detoxification of $\alpha$-tomatine by Botrytis cinerea. Physiol. Mol. Plant Pathol. 52:151-165.

Roldán-Arjona, T., Pérez-Espinosa, A., and Ruiz-Rubio, M. 1999. Tomatinase from Fusarium oxysporum f. sp. lycopersici defines a new class of saponinases. Mol. Plant-Microbe Interact. 12:852-861.

Ron, M., and Avni, A. 2004. The receptor for the fungal elicitor ethyleneinducing xylanase is a member of a resistance-like gene family in tomato. Plant Cell 16:1604-1615.

Rooney, H. C. E., Van't Klooster, J. W., van der Hoorn, R. A. L., Joosten, M. H., Jones, J. D. G., and de Wit, P. J. 2005. Cladosporium Avr2 inhibits tomato Rcr3 protease required for $C f$-2-dependent disease resistance. Science 308:1783-1786.

Ruoslahti, E. 1996. RGD and other recognition sequences for integrins. Annu. Rev. Cell Dev. Biol. 12:697-715.

Sanchez-Vallet, A., Saleem-Batcha, R., Kombrink, A., Hansen, G., Valkenburg, D.-J., Thomma, B. P. H. J., and Mesters, J. R. 2013. Fungal effector Ecp6 outcompetes host immune receptor for chitin binding through intrachain LysM dimerization. elife 2. Published online.

Schlumbaum, A., Mauch, F., Vogeli, U., and Boller, T. 1986. Plant chitinase are potent inhibitors of fungal growth. Nature 324:365-367. 
Senchou, V., Weide, R., Carrasco, A., Bouyssou, H., Pont-Lezica, R., Govers, F., and Canut, H. 2004. High affinity recognition of a Phytophthora protein by Arabidopsis via an RGD motif. Cell. Mol. Life Sci. 61:502-509.

Shibuya, N., Kaku, H., Kuchitsu, K., and Maliarik, M. J. 1993. Identification of a novel high-affinity binding site for $\mathrm{N}$-acetylchitooligosaccharide elicitor in the membrane fraction from suspension-cultured rice cells. FEBS Lett. 329:75-78.

Shindo, T., Kaschani, F., Yang, F., Kovács, J., Tian, F., Kourelis, J., Hong, T. N., Colby, T., Shabab, M., Chawla, R., Kumari, S., Ilyas, M., Hörger, A. C., Alfano, J. R., and van der Hoorn, R. A. L. 2016. Screen of nonannotated small secreted proteins of Pseudomonas syringae reveals a virulence factor that inhibits tomato immune proteases. PLoS Pathog. 12:e1005874.

Shindo, T., Misas-Villamil, J. C., Hörger, A. C., Song, J., and van der Hoorn, R. A. L. 2012. A role in immunity for Arabidopsis cysteine protease RD21, the ortholog of the tomato immune protease C14. PLoS One 7:e29317.

Song, J., Win, J., Tian, M., Schornack, S., Kaschani, F., Ilyas, M., van der Hoorn, R. A. L., and Kamoun, S. 2009. Apoplastic effectors secreted by two unrelated eukaryotic plant pathogens target the tomato defense protease Rcr3. Proc. Natl. Acad. Sci. U.S.A. 106:1654-1659.

Stergiopoulos, I., van den Burg, H. A., Okmen, B., Beenen, H. G., van Liere, S., Kema, G. H. J., and de Wit, P. J. G. M. 2010. Tomato Cf resistance proteins mediate recognition of cognate homologous effectors from fungi pathogenic on dicots and monocots. Proc. Natl. Acad. Sci. U.S.A. 107:7610-7615.

Tanaka, S., Brefort, T., Neidig, N., Djamei, A., Kahnt, J., Vermerris, W., Koenig, S., Feussner, K., Feussner, I., and Kahmann, R. 2014. A secreted Ustilago maydis effector promotes virulence by targeting anthocyanin biosynthesis in maize. elife 3 .

Tian, M., Win, J., Song, J., van der Hoorn, R., van der Knaap, E., and Kamoun, S. 2007. A Phytophthora infestans cystatin-like protein targets a novel tomato papain-like apoplastic protease. Plant Physiol. 143:364-377.
Valette-Collet, O., Cimerman, A., Reignault, P., Levis, C., and Boccara, M. 2003. Disruption of Botrytis cinerea pectin methylesterase gene Bcpme1 reduces virulence on several host plants. Mol. Plant-Microbe Interact. 16:360-367.

van den Burg, H. A., Harrison, S. J., Joosten, M. H. A. J., Vervoort, J., and de Wit, P. J. G. M. 2006. Cladosporium fulvum Avr4 protects fungal cell walls against hydrolysis by plant chitinases accumulating during infection. Mol. Plant-Microbe Interact. 19:1420-1430.

van der Hoorn, R. A. L. 2008. Plant proteases: From phenotypes to molecular mechanisms. Annu. Rev. Plant Biol. 59:191-223.

van Esse, H. P., Bolton, M. D., Stergiopoulos, I., de Wit, P. J. G. M., and Thomma, B. P. H. J. 2007. The chitin-binding Cladosporium fulvum effector protein Avr4 is a virulence factor. Mol. Plant-Microbe Interact 20:1092-1101.

van Esse, H. P., Van't Klooster, J. W., Bolton, M. D., Yadeta, K. A., van Baarlen, P., Boeren, S., Vervoort, J., de Wit, P. J. G. M., and Thomma, B. P. H. J. 2008. The Cladosporium fulvum virulence protein Avr2 inhibits host proteases required for basal defense. Plant Cell 20:1948-1963.

Whisson, S. C., Boevink, P. C., Wang, S., and Birch, P. R. J. 2016. The cell biology of late blight disease. Curr. Opin. Microbiol. 34:127-135.

Zhang, L., Kars, I., Essenstam, B., Liebrand, T. W. H., Wagemakers, L., Elberse, J., Tagkalaki, P., Tjoitang, D., van den Ackerveken, G., and van Kan, J. A. L. 2014. Fungal endopolygalacturonases are recognized as microbe-associated molecular patterns by the Arabidopsis receptor-like protein RESPONSIVENESS TO BOTRYTIS POLYGALACTURONASES1. Plant Physiol. 164:352-364.

Zhang, W., Fraiture, M., Kolb, D., Löffelhardt, B., Desaki, Y., Boutrot, F. F. G., Tör, M., Zipfel, C., Gust, A. A., and Brunner, F. 2013. Arabidopsis receptor-like protein 30 and receptor-like kinase suppressor of BIR1-1/EVERSHED mediate innate immunity to necrotrophic fungi. Plant Cell 25:4227-4241.

Zhao, Z., Liu, H., Wang, C., and Xu, J.-R. 2013. Comparative analysis of fungal genomes reveals different plant cell wall degrading capacity in fungi. BMC Genomics 14 